\title{
Festival de la Catrina
}

Karla Venecia López Romo

Profesora de la Licenciatura en Artes Plásticas

volaverunt@gmail.com

Al finalizar el mes de Octubre se realiza en la Universidad de Sonora el Festival de la Catrina, celebración que desde el 2008 se lleva a cabo por iniciativa de estudiantes de la Licenciatura en Artes Plásticas con el apoyo de sus profesores.

Desde hace tres años el festival se organiza con el respaldo de la Dirección de Vinculación y Difusión, desde entonces la invitación se ha hecho extensiva a toda la comunidad estudiantil y se ha ofrecido un incentivo económico para premiar los diferentes concursos a los que se convoca.

Año con año ha aumentado la participación de los estudiantes en el festival, en esta ocasión la afluencia de gente también fue inédita, había alumnos de diferentes escuelas, familiares, amigos y público en general recorriendo los interiores del edificio de la Licenciatura en Artes, donde se llevó acabo el montaje de las piezas para los tres concursos que se realizaron: el de altares, el de calaveras de cartonería y el de catrinas vivientes. En el recorrido estaba incluida una exposición de dibujo, pintura y gráfica, que organizaron los alumnos con sus propios trabajos académicos. Por fuera del edificio de Artes Plásticas se montó el escenario por donde desfilaron las catrinas, el evento fue dirigido por el maestro Darío Sotelo, docente de diseño gráfico y de los talleres libres de artes plásticas, que fungió como maestro de ceremonias. Como jurados de los diferentes concursos se presentaron las profesoras Rocío de Fátima Sánchez Castillo y Norma Alicia Villaseñor Fimbres de la Licenciatura en Artes Plásticas y la profesora Ana Isabel Campillo de la licenciatura en Artes Escénicas y Música.

Se contó con la participación del grupo de música tradicional Aires de Son, dirigido por el Mtro. Rafael Rodríguez,

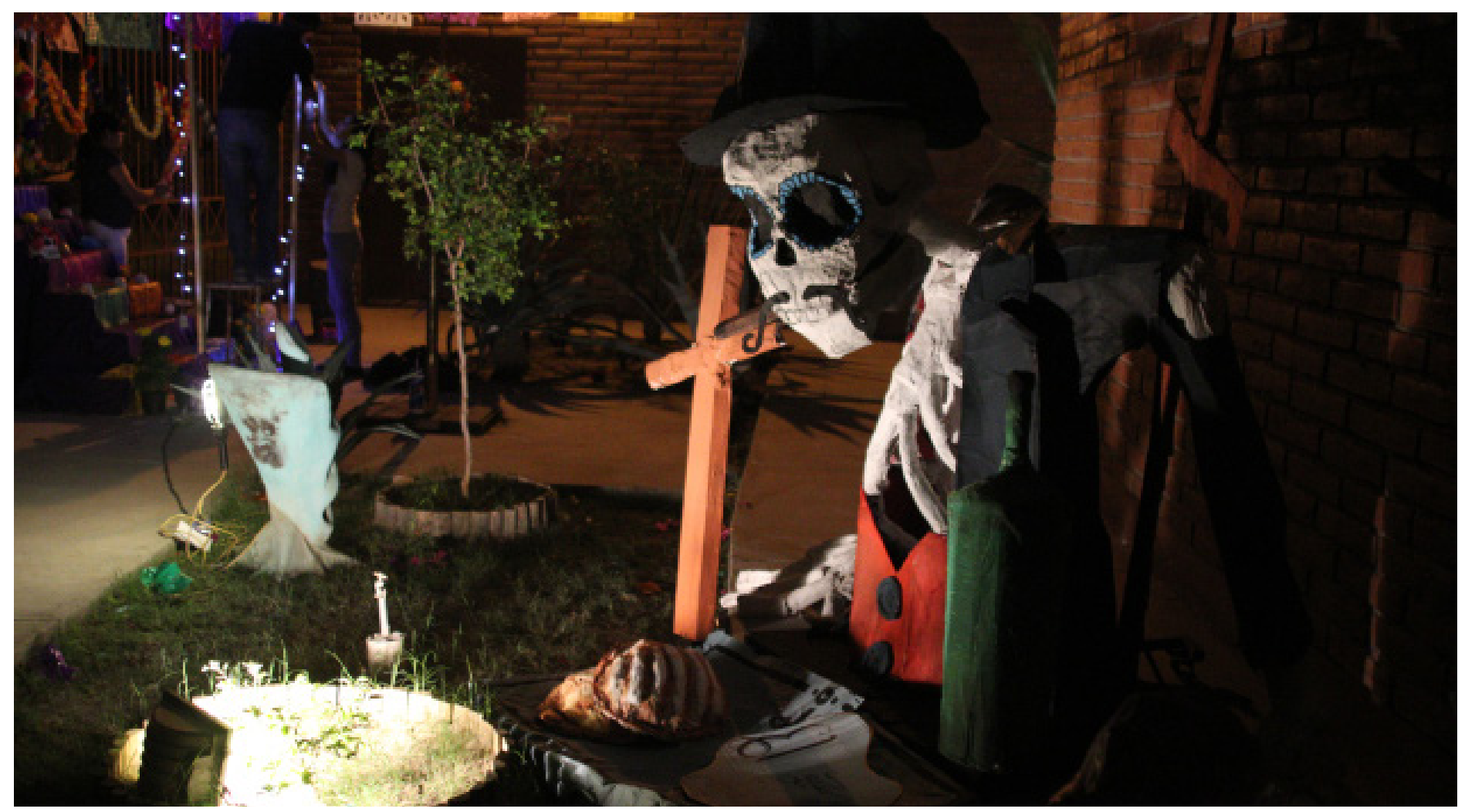


quienes amenizaron tocando Son Jarocho, mientras bailarines ataviados con trajes típicos movían sus faldas al ritmo del son. Además se contó con la presentación de un cuarteto de alumnos de la Licenciatura en Música y por su parte la Licenciatura en Literaturas Hispánicas participó con una serie lecturas poéticas que amenizaron la noche.

La escuela de Artes Plásticas lucía llena de colores: papel picado y caminos iluminados por la luz de las velas dirigían al público por diferentes rincones donde los altares y las calaveras enormes parecían cobrar vida bajo la luz trémula y las flores. Cabe mencionar que la decoración fue realizada con semanas de antelación por los mismos estudiantes, quienes se movilizaron por equipos para cubrir todos los detalles.

A un lado del escenario, se montó un Tzomplantli, altar tradicional de las culturas precolombinas, decorado por cráneos de piedra, que después sostendría en sus estacas las cabezas obtenidas de los sacrificios humanos. El Tzompantli realizado por los estudiantes de plástica estaba formado por cráneos vaciados en yeso y policromados para dar

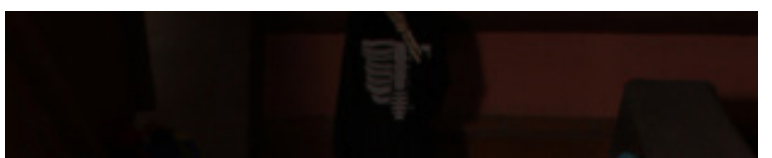
lugar lo ganó una alumna de Químico Biólogo María José Villela de Gurrola con la Reciclatrina. Su indumentaria estaba compuesta por diferentes materiales de reciclaje, sorprendía a los asistentes su elaborada falda de bolsas de "Tostitos". El tercer lugar lo ganó la alumna de Artes Plásticas Marielena Encinas Otero con la catrina de la Noche Estrellada, alusiva al cuadro de Van Gogh. Su vestido era hecho a mano y pintado por ella misma con la escena del cuadro del artista.

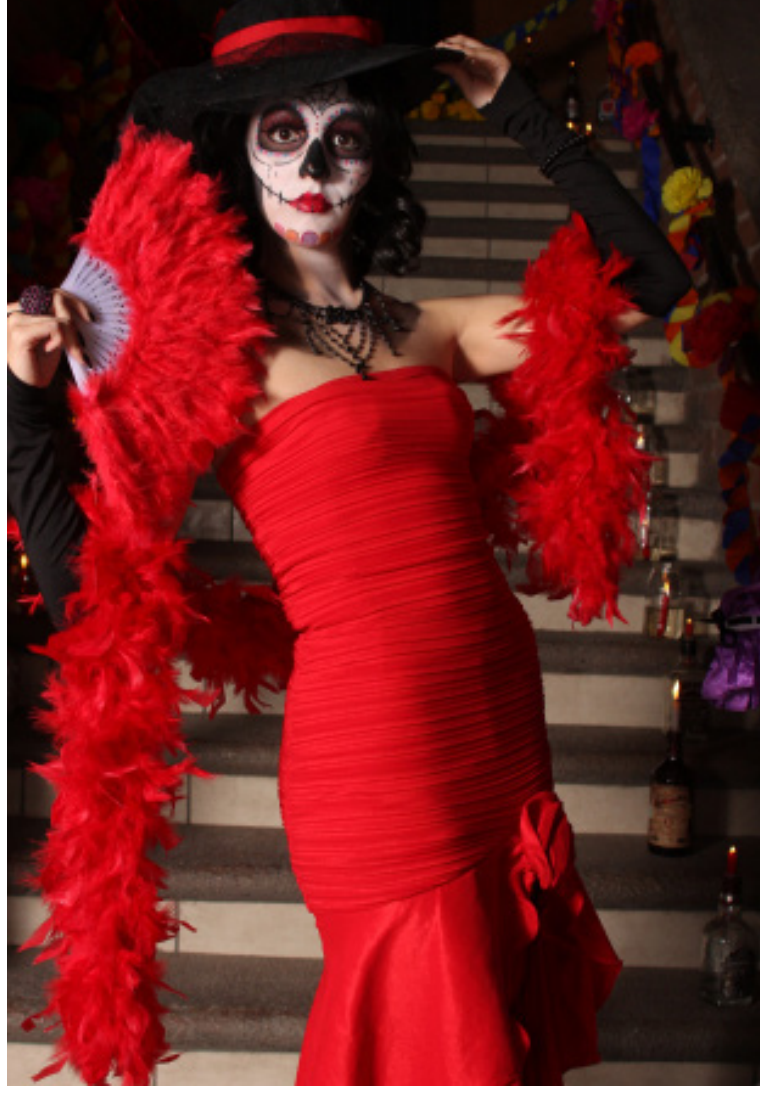

Fotografía: Alan Roberto Daniel Ortega un acabado similar al de la piedra,

o al de los huesos que han sido expuestos a la intemperie por años. Este era el lugar donde los participantes se preparaban para subir al escenario.

En los diferentes concursos participaron alumnos de Mercadotecnia, Biología, Químico Biólogo, Enfermería, Diseños Gráfico, Artes Plásticas, Artes Escénicas y Música. También se contó con la destacada participación de los alumnos de intercambio de Perú, Colombia y Argentina.

De Perú hubo dos participaciones en el concurso de catrinas, una fue una catrina tradicional y otra fue de Frida Khalo, Argentina participó con una calavera de Eva Perón y Colombia con la calavera de Policarpa Salvarrieta.

En el concurso de las catrinas vivientes ganó el primer lugar la calavera chola-chicana de Yail Melissa Barajas Olivas, alumna de la Licenciatura en Diseño Gráfico. El segundo

En el concurso de Altares los ganadores del primer lugar fueron estudiantes de la Licenciatura en Música con un altar dedicado a la maestra Emiliana de Zubeldía. Los estudiantes que participaron fueron Allam Enrique Jaime Aguilar y Karen Patricia Quintero Cabello. Los ganadores del segundo lugar fueron los alumnos de Artes Plásticas Rosa Isela Román Castillo, Gabriela del Castillo Acosta y Luis Meneses Ochoa, quienes dedicaron su altar a Chavela Vargas. El tercer lugar estaba dedicado al artista argentino Rogelio Polesello, realizado por las alumnas de Artes Plásticas Edith Susana Álvarez, María Fernanda Carmelo Castillo y Gabriela Delgado Romero.

El concurso de Catrinas de cartonería fue ganado por Mayra Janeth Dórame Calderón, estudiantes de Diseño Gráfico con la calavera de María Félix. El segundo lugar lo obtuvo Ana Sofía Grijalva Pineda, estudiante de Psicología, quien representó El Cristo Corpus Hypercubus, alusivo a la obra de Salvador Dalí. El tercer lugar lo ganaron los alumnos de Artes Plásticas Guillermo Alberto Carrillo Paco y Cristian Eduardo Navarro Villegas representando al Catrín: "el gustó por revivir".

Entre los altares concursantes se podía apreciar una interesante variedad de personajes del mundo de las artes plásticas, como Fancis Bacon, Lucian Freud y Remedios Varo. También se pudieron contemplar altares dedicados a obras plásticas, como el de Las Dos Fridas. Hubo algunas representaciones de catrinas tradicionales en los diferentes concursos. Entre las calaveras de cartonerías destacó una representación de Huitzilopochtli, realizada por el alumno Jesús Cicerol y la representación de Etnias Sonorenses, del alumno de Joaquín Durand, ambos de la Licenciatura en Artes Plásticas. 